\title{
Ampelopsis japonica ethanol extract suppresses migration and invasion in human MDA-MB-231 breast cancer cells
}

\author{
KYOUNG JIN NHO, JIN MI CHUN, DONG-SEON KIM and HO KYOUNG KIM \\ Herbal Medicine Resources Group, Korea Institute of Oriental Medicine, \\ Yuseong-gu, Daejeon 305-811, Republic of Korea
}

Received March 14, 2014; Accepted December 3, 2014

DOI: $10.3892 / \mathrm{mmr} .2015 .3179$

\begin{abstract}
Ampelopsis japonica (AJ) is a well-known traditional oriental herb with anti-inflammatory and anticancer activities. However, the molecular mechanisms by which AJ inhibits metastasis in breast cancer cells remain to be elucidated. The aim of the present study was to investigate the effects of AJ ethanol extract (EAJ) on highly metastatic human MDA-MB-231 breast cancer cells in vitro. AJ was extracted and chemically characterized. Cell proliferation was determined using a CCK-8 assay and migration was detected using a wound healing motility assay. A Transwell assay was used to evaluate the invasion and metastatic capabilities of the MDA-MB-231 cells. In addition, the mRNA expression levels of metalloproteinase (MMP)-2 and MMP-9 and tissue inhibitors of metalloproteinases (TIMP)-1 and TIMP-2 were evaluated using reverse transcription quantitative polymerase chain reaction in vitro. The results of the present study characterized the signaling cascades that mediated the antimetastatic activity of AJ in the human MDA-MB-231 breast cancer cell line. EAJ significantly suppressed the migration and invasion of MDA-MB-231 cells in vitro and inhibited the expression of metalloproteinase (MMP)-2 and MMP-9. These findings identified the biological activity of EAJ in an in vitro model of cancer metastasis and provided a rationale for further investigation.
\end{abstract}

\section{Introduction}

Breast cancer, the fifth leading cause of cancer-associated mortality worldwide, has high rates of recurrence and metastasis, which makes the disease difficult to eradicate (1). Although improved screening techniques have assisted in detecting breast cancer at early stages and advances in treatment have markedly improved patient survival rates, tumor invasion and metastasis

Correspondence to: Dr Ho Kyoung Kim, Herbal Medicine Resources Group, Korea Institute of Oriental Medicine, 1672 Yuseong-daero, Yuseong-gu, Daejeon 305-811, Republic of Korea

E-mail: hkkim@kiom.re.kr

Key words: Ampelopsis japonica, invasion, migration, MDA-MB-231 cells, matrix metalloproteinases remain the major contributors in breast cancer-associated mortality (2). Therefore the inhibition of metastasis offers a potential strategy to minimize the spread of breast tumors and improve patient survival rates.

Tumor metastasis is the primary cause of mortality in patients with cancer, which occurs when malignant cells degrade the cellular basement membrane and spread to distant organs, resulting in the formation of secondary tumors (3). Degradation of the basement membrane and extracellular matrix (ECM) is achieved by various proteases, including matrix metalloproteinases (MMPs) (4), of which MMP-2 and MMP-9 are frequently overexpressed in malignant tumors and directly affect cancer cell invasion (5).

Traditional oriental herbs offer potential therapies for various diseases, including diabetes mellitus, cancer and hypertension (6-9). In addition, increasing evidence has demonstrated that certain herbs improve the efficacy and reduce the side effects of conventional cancer therapies in breast and prostate cancer $(10,11)$.

Ampelopsis japonica (AJ), a well-known traditional oriental herb, has long been used as an anti-inflammatory and antibacterial agent against skin inflammation and ulcerous diseases or burns of the skin, respectively (12-14), and as an antitumor agent (15). However, few studies have been performed in this area and the mechanisms underlying the antitumor activity of AJ remain to be elucidated. The aim of the present study was to investigate the effects of EAJ on the invasion and migration of MDA-MB-231 breast cancer cells in vitro and to elucidate the associated signaling pathways.

\section{Materials and methods}

Chemicals and materials. All plastic materials, including cell culture vessels, flasks, Petri dishes, roller bottle and multi-well plates, were purchased from BD Falcon Labware (Franklin Lakes, NJ, USA). Fetal bovine serum (FBS), phosphate-buffered saline (PBS) and penicillin G/streptomycin were obtained from Gibco-BRL (Grand Island, NY, USA). RPMI-1640 medium was purchased from Welgene (Daegu, Korea). The CCK-8 assay kit was obtained from Dojindo Molecular Technologies, Inc. (Rockville, MD, USA). High-performance liquid chromatography (HPLC)-grade reagents, acetonitrile and water were obtained from J.T. Baker Chemical Co. (Phillipsburg, NJ, USA). Catechin, 
resveratrol standards and other chemicals were purchased from Sigma-Aldrich (St. Louis, MO, USA).

Preparation of the extract. AJ was purchased from Omniherb Co. (Yeoungcheon, Korea) as a dried herb and was authenticated based on microscopic and macroscopic characteristics by the Classification and Identification Committee of the Korea Institute of Oriental Medicine (KIOM; Daejeon, Korea). The committee was composed of nine experts in the fields of plant taxonomy, botany, pharmacognosy and herbology. A voucher specimen (no. KIOM 108-29A) was deposited at the herbarium of the Department of Herbal Resources Research in KIOM. The dried bark of AJ (200 g) was extracted twice using $70 \%$ ethanol (with $2 \mathrm{~h}$ reflux) and the extract was concentrated under reduced pressure. The decoction was then filtered, lyophilized and stored at $4{ }^{\circ} \mathrm{C}$ until further use. The yield of dried extract from the initial crude materials was $\sim 15.56 \%$ (w/w). The lyophilized powder was dissolved in $10 \%$ dimethyl sulfoxide and then filtered through a $0.22 \mu \mathrm{m}$ syringe filter to create a stock solution.

Cell culture. Human breast (MDA-MB-231) and liver (HepG2 and Hep3b) cancer cell lines were obtained from the American Type Culture Collection (ATCC; Rockville, MD, USA). The MDA-MB-231 cells were cultured in RPMI-1640 and liver cancer cells (HepG2 and Hep3b) were cultured in Eagle's Minimum Essential Medium (EMEM; ATCC) supplemented with $10 \%$ FBS, $100 \mathrm{U} / \mathrm{ml}$ penicillin and $100 \mu \mathrm{g} / \mathrm{ml}$ streptomycin in a humidified atmosphere of $5 \% \mathrm{CO}_{2}$ at $37^{\circ} \mathrm{C}$. The medium was replaced every three days.

Cell viability assay. WST-8, the active agent in the Cell Counting kit-8 (CCK-8) cell viability assessment, is reduced to yellow water-soluble formazan by the dehydrogenase released from mitochondria. A CCK-8 assay kit was used to determine the cell viability of AJ ethanol extract (EAJ)-treated cells and the absorbance was measured at $450 \mathrm{~nm}$ using a Benchmark Plus Microplate Spectrophotometer (Bio-Rad Laboratories, Inc., Hercules, CA, USA). HepG2, Hep3b and MDA-MB-21 cells were exposed to various concentrations of $\operatorname{EAJ}(0,25,50,100,200$ or $400 \mu \mathrm{g} / \mathrm{ml})$ for $24 \mathrm{~h}$. MDA-MB-231 cells were exposed to the various concentrations of $\operatorname{EAJ}(0,10,25,50,100,150,200,300$ or $400 \mu \mathrm{g} / \mathrm{ml})$ for 9,12 or $24 \mathrm{~h}$. Cell viability was then assessed using a CCK-8 assay. Cytotoxicity was expressed as a percentage of the absorbance measured in the untreated control cells.

Wound healing motility assay. The MDA-MB-231 cells were plated in 12-well plates at a density of $5 \times 10^{5}$ cells/well and cultured in medium containing $10 \%$ FBS until the cells were reached $\sim 70-80 \%$ confluence as a monolayer. The monolayer was carefully wounded using a yellow pipette tip and the cellular debris was removed by washing with RPMI-1640. The wounded monolayer was incubated with or without EAJ $(25,50,100$ or $150 \mu \mathrm{g} / \mathrm{ml})$ for 12 and $24 \mathrm{~h}$ in RPMI-1640 medium containing $10 \% \mathrm{FBS}$, as a chemoattractant or $1 \% \mathrm{FBS}$, as a control. Images were captured of the cell migration into the wounded area using phase contrast microscopy (Olympus IX53; Olympus Corp., Tokyo, Japan). The migratory cells were quantified and the percentage of inhibition was expressed based on the untreated control wells. The degree of wound closure or invasion was determined using inverted microscopy (Olympus IX53) and ImageJ analysis (version, IJ 1.46r; National Institutes of Health, Bethesda, MA, USA) to measure percent closure of the wounded area within the captured images. Briefly, from the wound area, the average wound width was obtained by dividing the area by the length of the analyzed region. The obtained wound widths were plotted against time in Microsoft Excel software (2010; Microsoft Corp., Redmond, WA, USA), and a linear fit was generated for each dataset. The slope of the linear fit was used as a measure of cell migration.

Cell invasion assay. The MDA-MB-231 cells were evaluated in Transwell inserts with $8 \mu \mathrm{m}$ pores (Corning Life Science, Inc, Tewksbury, MA, USA). The upper surface of the Transwell membrane was coated with Matrigel $(5 \mu \mathrm{g})$, while the lower compartment of the chamber was filled with $500 \mu$ l RPMI-1640 medium containing 1\% FBS (control). The cells $\left(5 \times 10^{5}\right)$ were seeded onto the upper part of each Transwell in serum-free RPMI-1640 medium containing different concentrations of EAJ $(50,100$ or $150 \mu \mathrm{g} / \mathrm{ml})$ for $24 \mathrm{~h}$. The cells were allowed to invade through the Matrigel for $24 \mathrm{~h}$ at $37^{\circ} \mathrm{C}$ in $5 \% \mathrm{CO}_{2} / 95 \%$ air and were then stained with Giemsa for $15 \mathrm{~min}$. The upper surface of the membrane was scraped with a cotton swab and, when the invasive cells reached the bottom surface of the porous filter, images were captured and the cells were counted. The percentage inhibition was expressed as a percentage of the untreated control wells.

Reverse transcription quantitative polymerase chain reaction $(R T-q P C R)$. The cells were lysed, and total RNA was isolated with an easy-BLUE total extraction kit (Intron, Seoul, Korea) according to the manufacturer's instructions. For cDNA synthesis, $1 \mu \mathrm{g}$ total RNA was mixed with Maxime RT premix (Intron) containing oligo dT primers and DEPC-treated water to a final volume of $20 \mu \mathrm{l}$, and incubated at $45^{\circ} \mathrm{C}$ for $60 \mathrm{~min}$. The reaction was stopped by heat inactivation at $95^{\circ} \mathrm{C}$ for $5 \mathrm{~min}$. RT-qPCR was performed using a Rotor-Gene 3000 system (Corbett Research, Sydney, Australia) with SYBR Green Master mix (Qiagen, Tokyo, Japan). All reactions were carried out according to the following protocol: $94^{\circ} \mathrm{C}$ for $2 \mathrm{~min}$, followed by 35 cycles of $94^{\circ} \mathrm{C}$ for $20 \mathrm{sec}, 60^{\circ} \mathrm{C}$ for $20 \mathrm{sec}$ and $72^{\circ} \mathrm{C}$ for $30 \mathrm{sec}$. The percentage of target gene expression relative to the control was normalized to the expression of glyceraldehyde 3-phosphate dehydrogenase (GAPDH; internal control) using $2^{-\Delta \Delta \mathrm{Ct}}$ analysis. Primers for the target genes were designed using Primer 3 software (Table I) (16).

High-performance liquid chromatography analysis. The samples were analyzed using reverse phase high-performance liquid chromatography with the Waters Alliance 2695 system (Waters Co., Milford, MA, USA) coupled with a 2996 Photodiode Array Detector (Waters Co.). A Phenomenex Luna C18 column (250x4.6 mm; particle size, $5 \mu \mathrm{m}$; Phenomenex, Torrance, CA, USA) was used as the stationary phase and the mobile phase was composed of $0.1 \%$ $(v / v)$ trifluoroacetic aqueous solution (A) and acetonitrile 
Table I. Sequences of the primers used in reverse transcription quantitative polymerase chain reaction analysis.

\begin{tabular}{lllcr}
\hline Gene & \multicolumn{1}{c}{ Forward } & \multicolumn{1}{c}{ Reverse } & Accession number & Length (bp) \\
\hline MMP-2 & CAGAATACCATCGAGACCAT & ATGTGATCTGGTTCTTGTCC & NM_004530 & 106 \\
MMP-9 & CCACTACTGTGCCTTTGAGT & TCCCATCCTTGAACAAATAC & NM_004994 & 102 \\
TIMP1 & TGGACTCTTGCACATCACTA & GATGGATAAACAGGGAAACA & NM_003254 & 133 \\
TIMP2 & GCTCTGTTGATTTTGTTCC & CTGCTTGTCAACTTTCAACA & NM_003255 & 125 \\
GAPDH & TCAAGCTCATTTCCTGGTAT & GTGAGGGTCTCTCTCTTCCT & NM_002046 & 141 \\
\hline
\end{tabular}

MMP, metalloproteinase; TIMP, tissure inhibitor of MMP; GAPDH, glyceraldehyde 3-phosphate dehydrogenase.



Figure 1. EAJ reduces the viability of MDA-MB-231 breast cancer cells. (A) HepG2, Hep3b and MDA-MB-21 cells were exposed to various concentrations of EAJ $(0,25,50,100,200$ or $400 \mu \mathrm{g} / \mathrm{ml})$ for $24 \mathrm{~h}$. (B) MDA-MB-231 cells were exposed to the indicated concentrations of EAJ for 9,12 or $24 \mathrm{~h}$. Cell viability was then assessed using a Cell Counting kit- 8 assay. Values are presented as the mean \pm standard deviation $(\mathrm{n}=3)$. ${ }^{*} \mathrm{P}<0.05{ }^{, * *} \mathrm{P}<0.01$ and ${ }^{* * * *} \mathrm{P}<0.001$, vs. control. (C) Cell morphology was examined under an inversion microscope following treatment of MDA-MB-231 cells with the indicated concentrations of EAJ magnification, x200). EAJ, Ampelopsis japonica ethanol extract; CON, control (0 $\mu \mathrm{g} / \mathrm{ml} \mathrm{EAJ})$.

(B). The elution conditions were as follows: At 0 min, the mobile phase consisted of $90 \% \mathrm{~A} / 10 \% \mathrm{~B}$ and was held for $10 \mathrm{~min}$. Between 10 and $40 \mathrm{~min}$, a gradient was applied to $60 \% \mathrm{~A} / 40 \% \mathrm{~B}$. This was followed by washing with $100 \% \mathrm{~B}$ for $5 \mathrm{~min}$ and a 15 min equilibration period in $90 \% \mathrm{~A} / 10 \% \mathrm{~B}$. The separation temperature was maintained at $40^{\circ} \mathrm{C}$ throughout the analysis, with a flow rate of $1.0 \mathrm{ml} / \mathrm{min}$ and an injection volume of $20 \mu \mathrm{l}$. Identification was based on the retention time and ultraviolet (UV) spectra compared with that of commercial standards, catechin and resveratrol. The components were quantified based on peak areas at the maximal wavelength. Calibration curves of the standards, ranging between 6.25 and $200 \mu \mathrm{g} / \mathrm{ml}$ (six levels), revealed good linearity with $\mathrm{R}^{2}$ values $>0.99$ (peak areas, vs. concentration).

Statistical analysis. Statistical analyses were performed using GraphPad Prism 5 software (GraphPad Software, Inc.,
La Jolla, CA, USA). One-way and two-way analysis of variance were followed by Dunnett's post-hoc test. $\mathrm{P}<0.05$ was considered to indicate a statistically significant difference.

\section{Results}

Effect of EAJ on the proliferation of MDA-MB-231 cells. The cytotoxic effect of EAJ on three cancer cell lines (HepG2, Hep3b and MDA-MB-231) was evaluated using a CCK-8 assay. The results demonstrated that EAJ reduced the viability of each of these cell lines in a concentration-dependent manner (Fig. 1A). In addition, EAJ was shown to have a weaker effect on the viability of MDA-MB-231 cells compared with the HepG2 and Hep3b cells. EAJ reduced the viability of the MDA-MB-231 cells to $70 \%$ of the control in a concentration- and time-dependent manner, with significant reduction in viability following exposure to $200-400 \mu \mathrm{g} / \mathrm{ml}$ EAJ for 12 or $24 \mathrm{~h}$ (Fig. 1B). Based on these results, non-cytotoxic concentrations of EAJ 
A
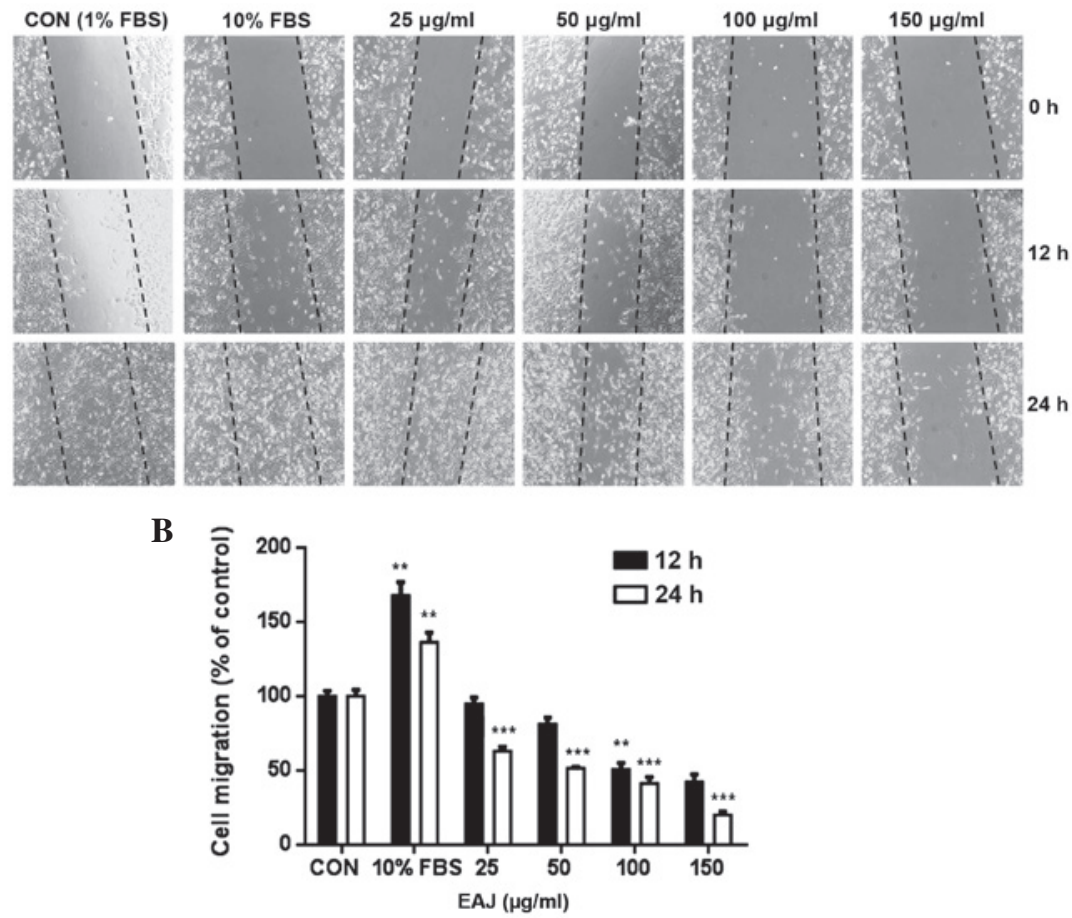

Figure 2. EAJ reduces the migration of MDA-MB-231 breast cancer cells. Cells were exposed to 25, 50, 100 or $150 \mu \mathrm{g} / \mathrm{ml} \mathrm{EAJ}$ for 24 and $48 \mathrm{~h}$ and control groups were incubated with $1 \%$ FBS or 10\% FBS, which acted as a chemoattractant. (A) Migration of cells into the wound (outlined by dashed lines) was observed using an inverted phase contrast microscope (magnification, x200). (B) Quantitative assessment of the number of cells in the denuded zone is presented as the mean \pm standard deviation of three independent experiments. ${ }^{* *} \mathrm{P}<0.01$ and ${ }^{* * * *} \mathrm{P}<0.001$, vs. control. EAJ, Ampelopsis japonica ethanol extract; FBS, fetal bovine serum; CON, control (1\% FBS).

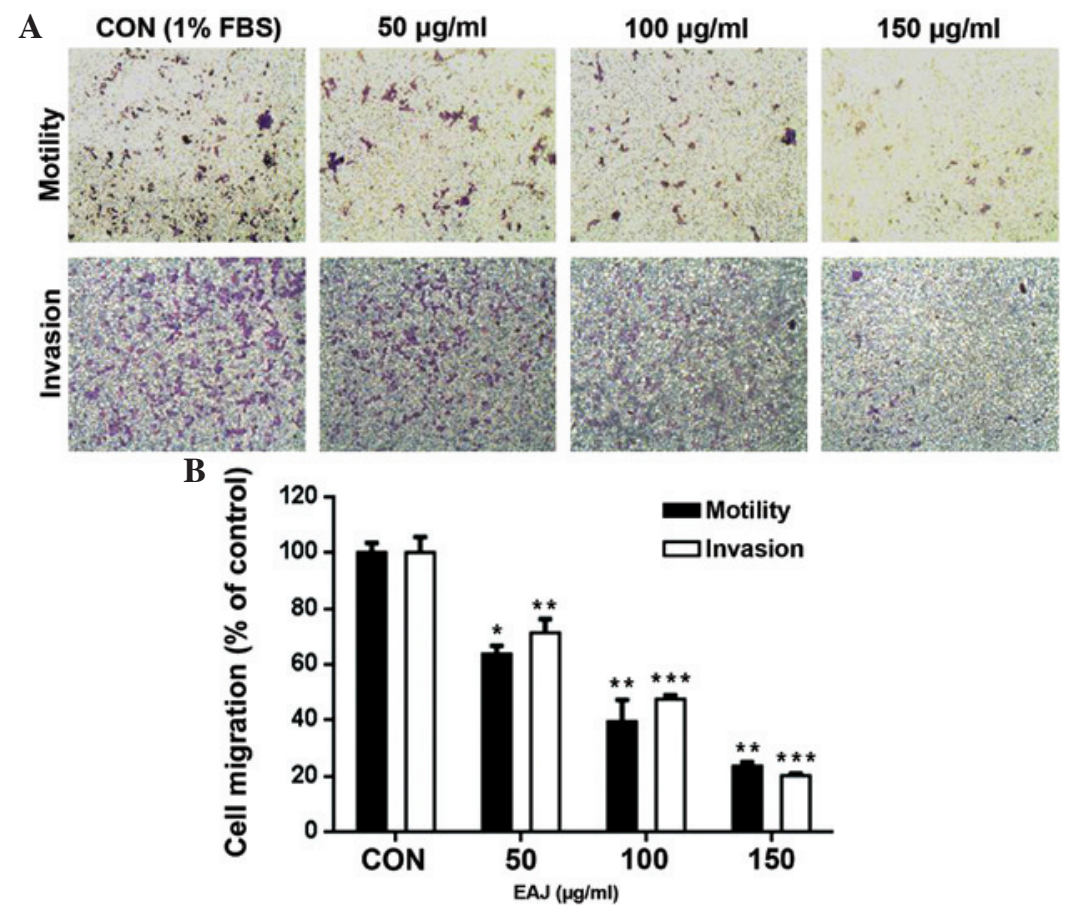

Figure 3. EAJ inhibits the invasion of MDA-MB-231 breast cancer cells. Transwell inserts, containing MDA-MB-231 cells and $1 \%$ serum, were placed in separate chambers with 50,100 or $200 \mu \mathrm{g} / \mathrm{ml} \mathrm{EAJ}$ with $10 \% \mathrm{FBS}$ and incubated for $24 \mathrm{~h}$ at $37^{\circ} \mathrm{C}$. The cells which crossed the Matrigel were fixed and stained with Giemsa and the number of cells were counted in six randomly selected fields. (A) Representative images of MDA-MB-231 cell invasion in the Transwell culture system (magnification, x200). (B) Quantification of the cells, which crossed the Matrigel-coated membrane. Values are presented as the mean \pm standard deviation ( $\mathrm{n}=3) .{ }^{*} \mathrm{P}<0.05,{ }^{* *} \mathrm{P}<0.01$ and ${ }^{* * * *} \mathrm{P}<0.001$, vs. control. EAJ, Ampelopsis japonica ethanol extract; FBS, fetal bovine serum; CON, control (10\% FBS)

$(25-150 \mu \mathrm{g} / \mathrm{ml})$ were used for further experiments. The lack of cytotoxicity was verified by assessing cell morphology (Fig. 1C).
Effect of EAJ on the migration of MDA-MB-231 cells. Cell migration is an important process in tumor metastasis. As 

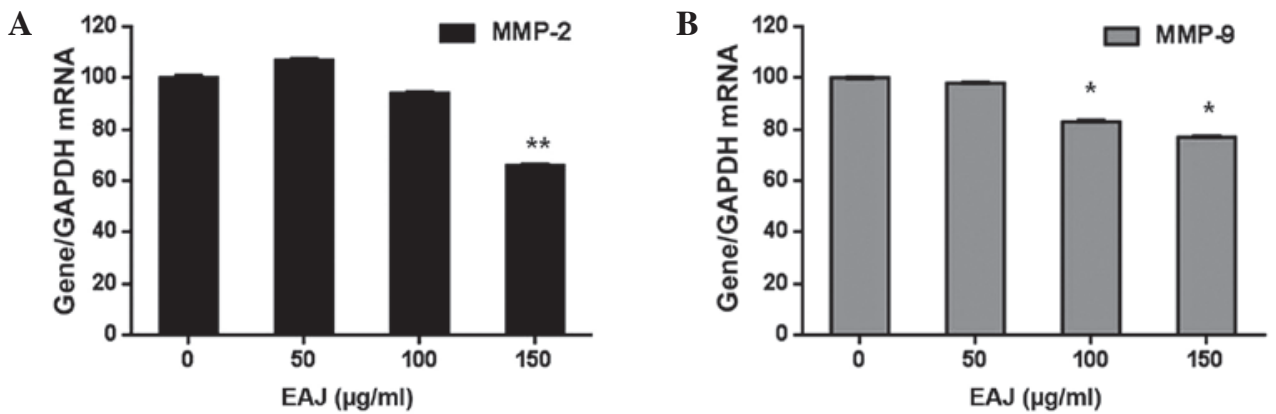

Figure 4. EAJ alters the mRNA expression levels of MMP-2 and MMP-9 in MDA-MB-231 breast cancer cells. Cells were exposed to various concentrations $(0,50$, 100 or $150 \mu \mathrm{g} / \mathrm{ml}$ ) of EAJ for $24 \mathrm{~h}$. The mRNA expression levels of (A) MMP-2 and (B) MMP-9 were measured using reverse transcription quantitative polymerase chain reaction. Values are presented as the mean \pm standard deviation $(\mathrm{n}=3)$. ${ }^{*} \mathrm{P}<0.05$ and ${ }^{* *} \mathrm{P}<0.01, \mathrm{vs} .0 \mu \mathrm{g} / \mathrm{ml}$ EAJ. EAJ, Ampelopsis japonica ethanol extract; MMP, metalloproteinase; GAPDH, glyceraldehyde 3-phosphate dehydrogenase.
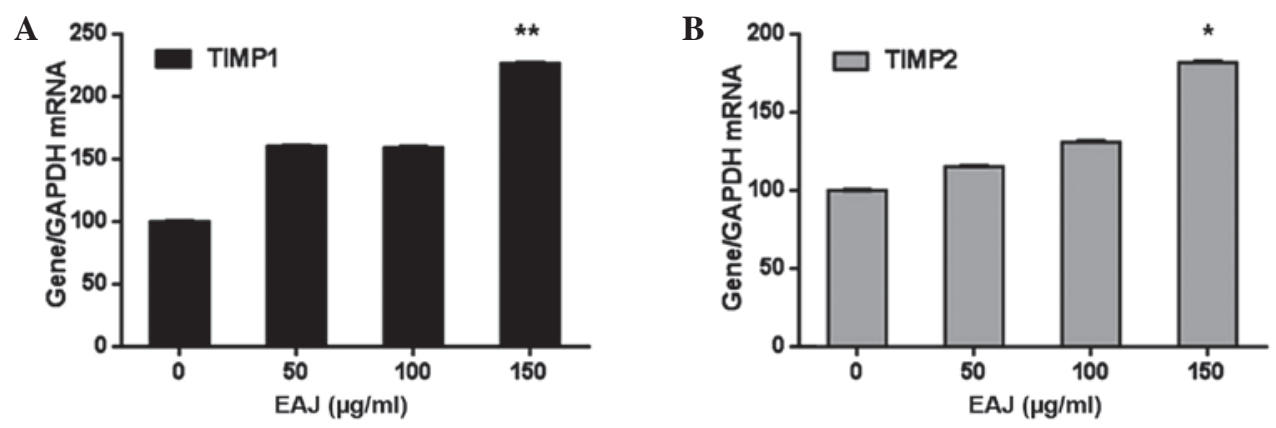

Figure 5. EAJ alters the mRNA expression levels of TIMP1 and TIMP2 in MDA-MB-231 breast cancer cells. The cells were exposed to various concentrations $(0,50,100$ or $150 \mu \mathrm{g} / \mathrm{ml})$ of EAJ for $24 \mathrm{~h}$. The mRNA levels of (A) TIMP1 and (B) TIMP2 by reverse transcription quantitative polymerase chain reaction. Values are presented as the mean \pm standard deviation $(\mathrm{n}=3)$. ${ }^{*} \mathrm{P}<0.05$ and ${ }^{* *} \mathrm{P}<0.01$, vs. $0 \mu \mathrm{g} / \mathrm{ml}$ EAJ. EAJ, Ampelopsis japonica ethanol extract; TIMP, tissue inhibitor of metalloproteinase. GAPDH, glyceraldehyde 3-phosphate dehydrogenase.

A

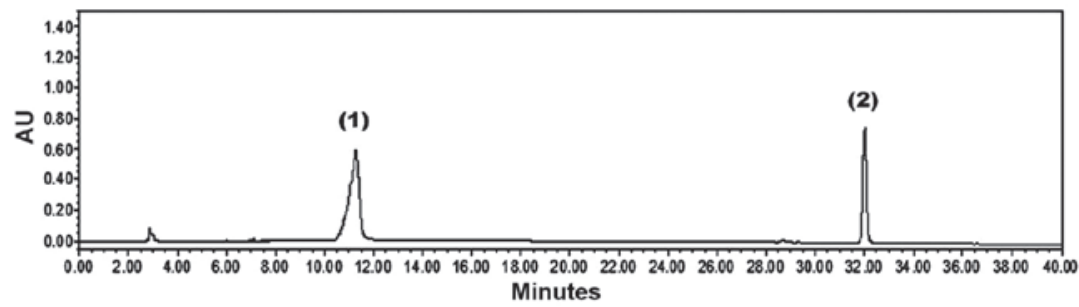

B

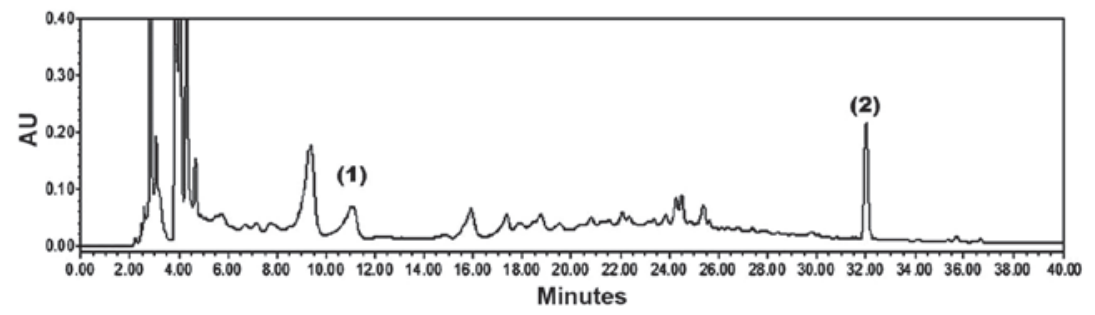

Figure 6. High performance liquid chromatography of the two standards. (A) Peaks represent standard compounds of (1) catechin and (2) resveratrol. (B) EAJ at $277 \mathrm{~nm}$. Catechin and resveratrol appeared at retention times of $\sim 11.05$ and $32.01 \mathrm{~min}$, respectively, which were similar to those of peaks 1 and 2 in the EAJ chromatogram. EAJ, Ampelopsis japonica ethanol extract; AU, absorbance units.

shown by the wound healing assay in Fig. 2A, 25-150 $\mu \mathrm{g} / \mathrm{mlEAJ}$ significantly inhibited MDA-MB-231 cell migration following incubation for $24 \mathrm{~h}$, whereas only those in 100 and $150 \mu \mathrm{g} / \mathrm{ml}$ EAJ were significantly inhibited after $12 \mathrm{~h}$ of incubation. As indicated by the densitometric analyses (Fig. 2B), $150 \mu \mathrm{g} / \mathrm{ml}$ EAJ decreased the migration of the MDA-MB-231 cells by $\sim 60$ and $80 \%$ at 12 and $24 \mathrm{~h}$, respectively. These results suggested that EAJ may effectively inhibit the migration of the highly invasive MDA-MB-231 cells.

Effect of EAJ on the invasion of MDA-MB-231 cells. Interactions between components of the cell matrix are important in cancer invasion. In the Transwell cell invasion assay, the motility and invasive ability of the MDA-MB-231 
cells were reduced in a concentration-dependent manner (Fig. 3A). In addition, quantitative analysis of these results demonstrated that exposure of the cells to $50,100,150 \mu \mathrm{g} / \mathrm{ml}$ EAJ for $24 \mathrm{~h}$ significantly reduced cell attachments to the Matrigel compared with the untreated control cells (Fig. 3B).

Effect of EAJ on the expression of MMP-2, MMP-9, tissue inhibitor of MMP (TIMP)1 and TIMP2. Since the overexpression and activation of MMPs is important in breast cancer cell invasion (17), the present study aimed to investigate whether the anti-invasive activity of EAJ correlated with the expression levels of MMP-2 and MMP-9. As shown in Fig. 4, EAJ inhibited the activities of MMP-2 and MMP-9 in a concentration-dependent manner, with significant reductions observed at $150 \mu \mathrm{g} / \mathrm{ml}$ EAJ for MMP-2 and 100 and $150 \mu \mathrm{g} / \mathrm{ml}$ EAJ for MMP-9. In addition, as the activity and expression of MMPs are tightly regulated by endogenous TIMPs (18), the transcription levels of TIMP1 and TIMP2 were determined by RT-qPCR. As shown in Fig. 5, EAJ increased the expression levels of TIMP1 and TIMP2 in a concentration-dependent manner, with significant increases observed at $150 \mu \mathrm{g} / \mathrm{ml}$ EAJ, while the mRNA expression levels of MMP-2 and MMP-9 decreased.

Identification and quantification of EAJ components. The present study identified two components of EAJ, catechin and resveratrol, using HPLC/PDA chromatograms and comparing retention time and UV spectra with commercial standards. As shown in Fig. 6, the HPLC analysis of EAJ identified two standards, catechin and resveratrol, which appeared at retention times of $\sim 11.05$ and $32.01 \mathrm{~min}$, respectively. The EAJ contained $3.15 \pm 0.07 \mathrm{mg} / \mathrm{g}$ catechin and $0.42 \pm 0.01 \mathrm{mg} / \mathrm{g}$ resveratrol.

\section{Discussion}

The invasion and metastasis of tumor cells occur through several complex processes, including cell adhesion, proteolytic extracellular matrix (ECM) degradation, cell migration into the circulatory system through basement membranes and tumor growth at the metastatic site (19). The dysregulation or inhibition of one of several of these processes offers one approach in antimetastatic therapy. The present study was the first, to the best of our knowledge, to demonstrate the significant inhibition of MDA-MB-231 cell invasion through the basement membrane following treatment with non-cytotoxic concentrations of EAJ. In addition, EAJ reduced cell motility, which is required for the migration of cells from primary to secondary tumor sites.

MMPs, a family of zinc-dependent endopeptidases, which degrade the collagen components of the ECM. MMPs also regulate migration, invasion, proliferation and apoptosis in various types of cell (20). MMP-2 and MMP-9, degrade the ECM and promote the release of key factors, which are important in tumor angiogenesis and the growth of several types of cancer (21-23). The results of the present study, demonstrated that EAJ inhibited the mRNA expression levels of MMP-2 and MMP-9 at the transcriptional level. In addition, MMPs have been implicated in the invasion of breast cancer cells, therefore, the downregulation of MMP-2 and MMP-9 may mediate the EAJ-induced inhibition of MDA-MB-231 cell invasion that was observed in the present study.
According to the HPLC analysis performed in the present study, EAJ contained catechin and resveratrol. Resveratrol, as a member of the stilbene family, is primary ingredient of wine $(24,25)$, which has been previously used in traditional Japanese and Chinese medicine for the treatment of fungal diseases, various types of skin inflammation and cardiovascular and liver diseases $(26,27)$. In addition, resveratrol has been found to have various therapeutic benefits, including antioxidant, antiproliferation and antitumor activities (28-30). Cathechin, green tea polyphenols, also exhibits antioxidant and antitumor activities $(31,32)$. It has been shown to the molecular mechanisms of their anticancer effects, including the suppression of cancer cell proliferation, induction of apoptosis, and inhibition of tumor metastasis and angiogenesis (33). The results of the present study confirmed the presence of resveratrol and catechin in EAJ at concentrations of 0.42 and $3.15 \mathrm{mg} / \mathrm{g}$, respectively, which, in part, explained the antitumor effect of EAJ. However, no other active compound was detected in EAJ. Further studies are required in order to clarify the pharmacological mechanisms of EAJ and to identify other potential compounds mediating its antimetastatic activity.

In conclusion, the present study indicated that EAJ may potentially arrest the progression of tumors by inhibiting invasion by suppressing the mRNA expression of MMP-2/-9 and upregulation of the mRNA expression of TIMP1/2 These results provided a theoretical foundation for the suitability of EAJ as a potential therapeutic agent for the treatment of breast cancer metastasis.

\section{Acknowledgements}

The present study was supported by grants from the Construction of the Basis for Practical Application of Herbal Resources (no. K12020), the ICT Fusional Construction of Alternative Herbal Medicine Resources (no. K14410) and the Korea Institute of Oriental Medicine to the Ministry of Science, ICT and Future Planning (Daejeon, Korea).

\section{References}

1. Ferlay J, Shin HR, Bray F, Forman D, Mathers C and Parkin DM: Estimates of worldwide burden of cancer in 2008: GLOBOCAN 2008. Int J Cancer 127: 2893-2917, 2010.

2. Coughlin SS and Ekwueme DU: Breast cancer as a global health concern. Cancer Epidemiol 33: 315-318, 2009.

3. Weber GF: Molecular mechanisms of metastasis. Cancer Lett 270: 181-190, 2008

4. Johansson N, Ahonen M and Kähäri VM: Matrix metalloproteinases in tumor invasion. Cell Mol Life Sci 57: 5-15, 2000.

5. Köhrmann A, Kammerer U, Kapp M, Dietl J and Anacker J: Expression of matrix metalloproteinases (MMPs) in primary human breast cancer and breast cancer cell lines. BMC Cancer 9: $188,2009$.

6. Wiwanitkit V: Thai ethnopharmacological herbs for diabetes treatment: data collection and informatics tracing for therapeutic property. Diabetes Metab Syndr 5: 103-104, 2011.

7. Kim JH, Kim MH, Yang G, Huh Y, Kim SH and Yang WM: Effects of topical application of Astragalus membranaceus on allergic dermatitis. Immunopharmacol Immunotoxicol 35: 151-156, 2013.

8. Han MH, Lee WS, Lu JN, et al: Citrus aurantium L. exhibits apoptotic effects on U937 human leukemia cells partly through inhibition of Akt. Int J Oncol 40: 2090-2096, 2012.

9. Mahassni SH and Al-Reemi RM: Apoptosis and necrosis of human breast cancer cells by an aqueous extract of garden cress (Lepidium sativum) seeds. Saudi J Biol Sci 20: 131-139, 2013. 
10. Chang EJ, Lee WJ, Cho SH and Choi SW: Proliferative effects of flavan-3-ols and propelargonidins from rhizomes of Drynaria fortunei on MCF-7 and osteoblastic cells. Arch Pharm Res 26 620-630, 2003

11. Lu J, Kim SH, Jiang C, Lee H and Guo J: Oriental herbs as a source of novel anti-androgen and prostate cancer chemopreventive agents. Acta Pharmacol Sin 28: 1365-1372, 2007.

12. Hong CH, Hur SK, Oh OJ, Kim SS, Nam KA and Lee SK: Evaluation of natural products on inhibition of inducible cyclooxygenase (COX-2) and nitric oxide synthase (iNOS) in cultured mouse macrophage cells. J Ethnopharmacol 83: 153-159, 2002.

13. Bae KH: The medicinal Plants of Korea. Edited by Hwang JS Korea: Kyo-Hak Publishing Co 328, 2000.

14. Suh BI and Jeong GY: Herbology. Edited by Lee JG Korea: Dae Gu Hanny University 108, 1987.

15. Kim JH, Ju EM, Lee DK and Hwang HJ: Induction of apoptosis by momordin I in promyelocytic leukemia (HL-60) cells. Anticancer Res 22: 1885-1889, 2002.

16. Koressaar T and Remm M: Enhancements and modifications of primer design program Primer3. Bioinformatics 23: 1289-1291, 2007.

17. Egeblad M and Werb Z: New functions for the matrix metalloproteinases in cancer progression. Nat Rev Cancer 2: 161-174, 2002

18. Hong S, Park KK, Magae J, et al: Ascochlorin inhibits matrix metalloproteinase-9 expression by suppressing activator protein-1-mediated gene expression through the ERK1/2 signalling pathway: inhibitory effects of ascochlorin on the invasion of renal carcinoma cells. J Biol Chem 280: 25202-25209, 2005.

19. Cairns RA, Khokha R and Hill RP: Molecular mechanisms of tumor invasion and metastasis: an integrated view. Curr Mol Med 3: 659-671, 2003.

20. Sternlicht MD and Werb Z: How matrix metalloproteinases regulate cell behavior. Ann Rev Cell Dev Biol 17: 463-516, 2001

21. Liotta LA and Stetler-Stevenson WG: Tumor invasion and metastasis: an imbalance of positive and negative regulation. Cancer Res 51 (18 Suppl): 5054s-5059s, 1991.

22. Kato Y, Yamashita T and Ishikawa M: Relationship between expression of matrix metalloproteinase-2 and matrix metalloproteinase-9 and invasion ability of cervical cancer cells. Oncol Rep 9: 565-569, 2002.
23. Gilabert-Estellés J, Ramón LA, España F, et al: Expression of angiogenic factors in endometriosis: relationship to fibrinolytic and metalloproteinase systems. Hum Reprod 22: 2120-2127, 2007.

24. Weng CJ, Yang YT, Ho CT and Yen GC: Mechanisms of apoptotic effects induced by resveratrol, dibenzoylmethane and their analogues on human lung carcinoma cells. J Agric Food Chem 57: 5235-5243, 2009.

25. Roy S, Sannigrahi S, Majumdar S, Ghosh B and Sarkar B Resveratrol regulates antioxidant status, inhibits cytokine expression and restricts apoptosis in carbon tetrachloride induced rat hepatic injury. Oxid Med Cell Longev 2011: 703676 , 2011.

26. Johnson WD, Morrissey RL, Usborne AL, et al: Subchronic oral toxicity and cardiovascular safety pharmacology studies of resveratrol, a naturally occurring polyphenol with cancer preventive activity. Food Chem Toxicol 49: 3319-3327, 2001.

27. Szekeres T, Saiko P, Fritzer-Szekeres M, Djavan B and Jäger W: Chemopreventive effects of resveratrol and resveratrol derivatives. Ann NY Acad Sci 1215: 89-95, 2011.

28. Fabre KM, Saito K, DeGraff W, et al: The effects of resveratrol and selected metabolites on the radiation and antioxidant response. Cancer Biol Ther 12: 915-923, 2011.

29. Scarlatti F, Sala G, Somenzi G, Signorelli P, Sacchi N and Ghidoni R: Resveratrol induces growth inhibition and apoptosis in metastatic breast cancer cells via de novo ceramide signaling. FASEB J 17: 2339-2341, 2003.

30. Kundu JK and Surh YJ: Cancer chemopreventive and therapeutic potential of resveratrol, mechanistic perspectives. Cancer Lett 269: 243-261, 2008

31. Castillo-Pichardo L and Dharmawardhane SF: Grape polyphenols inhibit Akt/mammalian target of rapamycin signaling and potentiate the effects of gefitinib in breast cancer. Nutr Cancer 64: 1058-1069, 2012

32. Islam S, Nasrin S, Khan MA, et al: Evaluation of antioxidant and anticancer properties of the seed extracts of Syzygium fruticosum Roxb. growing in Rajshahi, Bangladesh. BMC Complement Altern Med 13: 142, 2013.

33. Yu Y, Deng Y, Lu BM, Liu YX, Li J and Bao JK: Green tea catechins: a fresh flavor to anticancer therapy. Apoptosis 19: 1-18, 2014. 